See Article page 446.

\section{Commentary: Femoral arterial catheters for cardiac surgery: To do it or not to do it? That is the question}

\author{
Alex M. Wisniewski, MD, and \\ J. Hunter Mehaffey, MD, MSc
}

Among many other data points, proper hemodynamic monitoring during cardiopulmonary bypass is crucial because surgeons, anesthesiologists, and perfusionists rely on this data to make informed decisions on intraoperative patient management. Radial-to-femoral pressure gradient (RFPG) is defined as $\geq 25 \mathrm{~mm} \mathrm{Hg}$ systolic or $\geq 10 \mathrm{~mm} \mathrm{Hg}$ mean arterial pressure difference in radial and femoral pressures for a minimum of 5 consecutive minutes. ${ }^{1}$ It occurs in at least one-third to one-half of patients during cardiopulmonary bypass and may persist into the postoperative period. ${ }^{2,3}$ This discrepancy may lead to excessive and inappropriate vasoactive medication use during the perioperative timeframe. The mechanism of RFPG remains unclear, although certain risk factors such as short stature, complexity of operation, and prolonged aortic crossclamp time may play a role in identifying patients at risk for developing RFPG in whom a femoral arterial catheter should be placed. ${ }^{2}$ In the present study, the authors suggest smaller radial artery diameter as an additional data point to consider when determining sites of arterial pressure monitoring preoperatively. ${ }^{4}$

Bouchard-Dechêne and colleagues ${ }^{4}$ describe their prospective experience with RFPG and the role of radial artery diameter in identifying patients at greatest risk for developing this incongruity. The mechanism behind RFPG remains unclear, although vasomotor activity in muscular

\footnotetext{
From the Division of Cardiac Surgery, Department of Surgery, University of Virginia, Charlottesville, Va.

Disclosures: The authors reported no conflicts of interest.

The Journal policy requires editors and reviewers to disclose conflicts of interest and to decline handling or reviewing manuscripts for which they may have a conflict of interest. The editors and reviewers of this article have no conflicts of interest.

Received for publication Sept 8, 2021; accepted for publication Sept 17, 2021; available ahead of print Oct 4, 2021.

Address for reprints: J. Hunter Mehaffey, MD, MSc, Division of Cardiac Surgery, Department of Surgery, 1215 Lee St, PO Box 800679, Charlottesville, VA 22908 (E-mail: jhm9t@virginia.edu).

JTCVS Open 2021;8:463-4

2666-2736

Copyright (C) 2021 The Author(s). Published by Elsevier Inc. on behalf of The American Association for Thoracic Surgery. This is an open access article under the CC BY-NC-ND license (http://creativecommons.org/licenses/by-nc-nd/4.0/).

https://doi.org/10.1016/j.xjon.2021.09.027
}

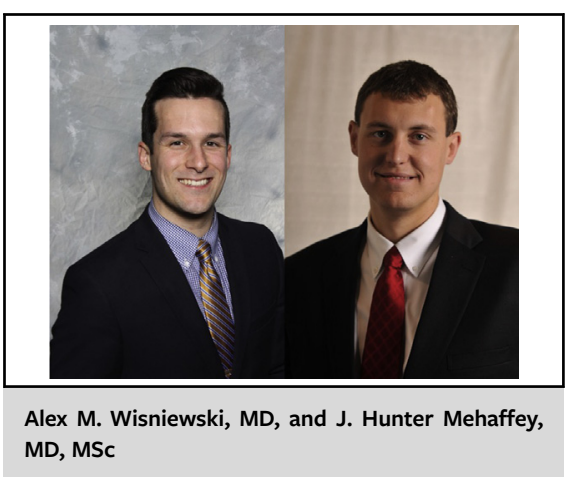

\begin{abstract}
CENTRAL MESSAGE
RFPG is a common with radial artery diameters $<1.8 \mathrm{~mm}$ and may be predictive of this phenomenon in which femoral artery pressure monitoring is warranted.
\end{abstract}

arteries as a response to catecholamines has been proposed. With smaller radial arteries, this vasoconstriction may lead to a diminished pulse pressure and a subsequent RFPG. The authors looked to prospectively quantify radial artery diameters in patients undergoing cardiac surgery. They demonstrate patients with a smaller radial artery diameter $(<1.8 \mathrm{~mm})$ were more likely to experience RFPG than those with larger diameters $(>2.2 \mathrm{~mm})$. Patients with a smaller radial artery diameter were also more likely be women, have a lower body weight, lower body mass index, and smaller body surface area. Radial artery diameter may indeed increase the risk of RFPG, although it likely serves as a proxy for known risk factors such as short stature.

When comparing single radial arterial monitoring to both radial and femoral arterial monitoring, those with single radial arterial monitoring, despite undergoing isolated procedures with shorter crossclamp and bypass times, received significantly more phenylephrine. In this study, the decision of which arterial lines were placed was at the discretion of the anesthesiologist. The authors state an institutional bias toward dual site monitoring in more complex procedures; this was confirmed by the higher rate of isolated procedures in the single radial catheter cohort. It is likely that those patients receiving more vasoactive medications in the single radial catheter group would have possessed a discrepancy between peripheral and central arterial pressures. Hence, utilization of a femoral arterial catheter may have alleviated 
this inappropriate phenylephrine use. Perhaps complexity of procedure taken alone is likely not a good predictor of RFPG unless used in addition to other risk factors. Thus, with such a high rate of RFPG in patients undergoing cardiac surgery and the subsequent clinical consequences of excessive vasoactive medication use, should all patients have femoral arterial monitoring?

Arterial lines do pose a small risk of bloodstream infection, which is increased with utilization of a femoral line. ${ }^{5}$ However, the overall rate of infection remains low, and these lines are typically removed early in the postoperative course. Specifically, femoral lines have risk of retroperitoneal hematoma, although use of small, $4 \mathrm{~F}$ catheters placed under ultrasound guidance likely mitigates this. Another concern with routine use of femoral arterial lines is the disruption of patient mobility postoperatively. The authors state no issue with this because all their patients are mobilized regardless of presence of a femoral catheter. Other studies have demonstrated that it is indeed safe to ambulate patients with femoral arterial lines and it therefore should not be a barrier to early mobility. ${ }^{6,7}$

The authors have confirmed known risk factors for RFPG with the addition of radial artery diameter as another tool in the toolbox for raising your suspicion of this intraoperative falsity. RFPG is a common occurrence and may result in inappropriate vasoactive medication use, although whether or not this translates to differences in patient outcomes is unknown from the present study. Femoral arterial catheter use is simple and effective in preventing this complication and should aid in reduction of erroneous vasoactive medication use. For patients with a combination of known risk factors for RFPG such as characteristics of short stature and radial artery diameters $<1.8 \mathrm{~mm}$, placement of a femoral arterial catheter should be considered.

\section{References}

1. Stern DH, Gerson JI, Allen FB, Parker FB. Can we trust the direct radial artery pressure immediately following cardiopulmonary bypass? Anesthesiology. 1985; 62:557-61.

2. Bouchard-Dechene V, Couture P, Su A, Deschamps A, Lamarche Y, Desjardins G, et al. Risk factors for radial-to-femoral artery pressure gradient in patients undergoing cardiac surgery with cardiopulmonary bypass. J Cardiothorac Vasc Anesth. 2018;32:692-8.

3. Fuda G, Denault A, Deschamps A, Bouchard D, Fortier A, Lambert J, et al. Risk factors involved in central-to-radial arterial pressure gradient during cardiac surgery. Anesth Analg. 2016;122:624-32.

4. Bouchard-Dechêne V, Kontar L, Couture P, Pérusse P, Levesque S, Lamarche Y, et al; Montreal Heart Institute Research Team. Radial-to-femoral pressure gradient quantification in cardiac surgery. J Thorac Cardiovasc Surg Open. 2021;8:446-60.

5. O'Horo JC, Maki DG, Krupp AE, Safdar N. Arterial catheters as a source of bloodstream infection: a systematic review and meta-analysis. Crit Care Med. 2014;42: 1334-9.

6. Perme C, Nalty T, Winkelman C, Kenji Nawa R, Masud F. Safety and efficacy of mobility interventions in patients with femoral catheters in the ICU: a prospective observational study. Cardiopulm Phys Ther J. 2013;24:12-7.

7. Damluji A, Zanni JM, Mantheiy E, Colantuoni E, Kho ME, Needham DM. Safety and feasibility of femoral catheters during physical rehabilitation in the intensive care unit. J Crit Care. 2013;28. 535.e9-535.e15. 